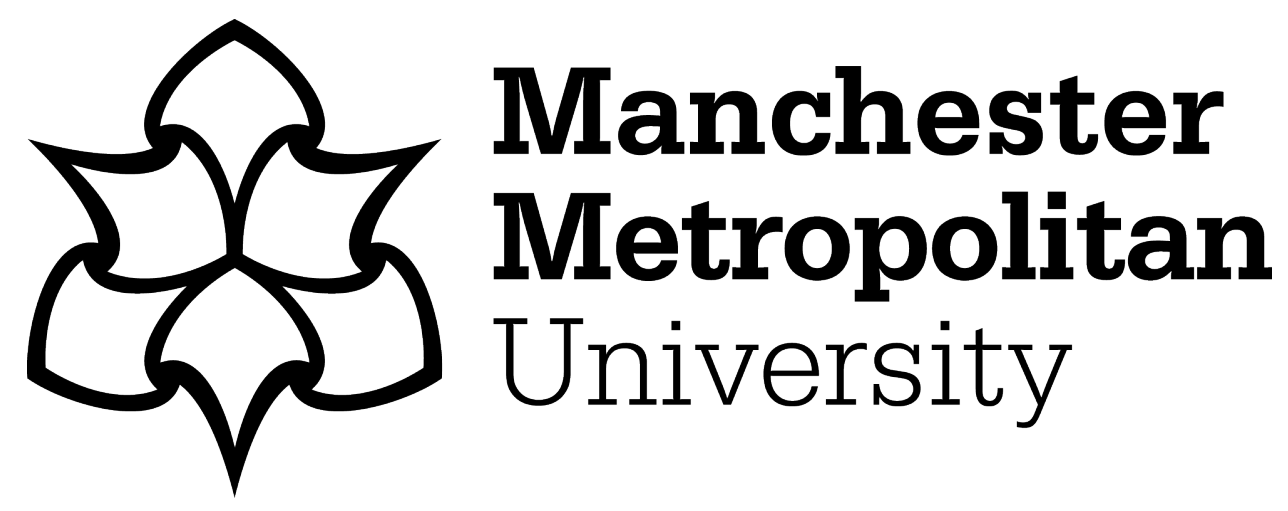

Campbell, Sarah ORCID logoORCID: https://orcid.org/0000-0002-29207318, Manthorpe, Jill, Samsi, Kritika, Abley, Clare, Robinson, Louise, Watts, Sue, Bond, John and Keady, John (2016) Living with uncertainty: Mapping the transition from pre-diagnosis to a diagnosis of dementia. Journal of Aging Studies, 37. pp. 40-47. ISSN 0890-4065

Downloaded from: https://e-space.mmu.ac.uk/625033/

Version: Accepted Version

Publisher: Elsevier BV

DOI: https://doi.org/10.1016/j.jaging.2016.03.001

Please cite the published version 


\title{
Living with uncertainty: Mapping the transition from pre-diagnosis to a diagnosis of dementia
}

\author{
Sarah Campbell a , Jill Manthorpe ${ }^{\text {b }}$, Kritika Samsi ${ }^{\text {b }}$, Clare Abley ${ }^{\text {, }}$, Louise Robinson ${ }^{\text {, }}$, Sue Watts ${ }^{\mathrm{d}, 1}$, \\ John Bond ${ }^{\mathrm{e}, 2}$, John Keady ${ }^{\mathrm{a}, *}$ \\ a Dementia and Ageing Research Team, School of Nursing, Midwifery and Social Work, The University of Manchester, UK \\ b Social Care Workforce Research Unit, King's College London, UK \\ c Institute for Ageing, Newcastle University, UK \\ d Greater Manchester West Mental Health NHS Foundation Trust, UK \\ e Newcastle University, UK
}

\begin{abstract}
A B S T R A C T
Across the world, an early and timely diagnosis of dementia is seen to be a policy and practice imperative and a necessary step in order to live well with the condition. However, limited understanding exists regarding the personal and relational meanings attributed to the diagnostic experience. Drawn from the findings of a larger multi-site study conducted in four areas of England, this article presents a subset of the data where five participants and their carers and two people living alone initially presented themselves at a memory clinic for diagnostic testing, with this presentation eventually resulting in a confirmed, and shared, diagnosis of dementia. All 12 participants were interviewed at two time points in the study: at the time of first presentation to the memory clinic and shortly after the diagnosis had been shared with them. Informed by the grounded theory method, constant comparative analysis was applied to the data and this process resulted in a four-phase sequential model of diagnostic transition: (1) becoming self-aware $\rightarrow$ seeking outside help; (2) being referred $\rightarrow$ receiving a clinic appointment; (3) undergoing tests $\rightarrow$ being told what's wrong; and (4) adjusting to the diagnosis $\rightarrow$ negotiating everyday expectations. Running through each phase was the core category of 'living with uncertainty' which summarised the entire diagnostic journey for all study participants. Findings suggest a need for better awareness and information for people living with dementia at all phases and time points in the condition, which may be fostered by embedding these in early clinical encounters.
\end{abstract}

(C) 2016 Elsevier Inc. All rights reserved.

\section{Introduction}

Worldwide, 36 million people live with dementia; these numbers are projected to double every 20 years to 66 million by 2030 and 115 million by 2050 with the most concentrated prevalence being in the developing world (Alzheimer's Disease International $[A D I], 2009)$. In the United Kingdom (UK), demographic data have revealed that there were 835,000 people who had a dementia in 2014 (Alzheimer's Society's,

\footnotetext{
* Corresponding author.

1 Now retired, formerly.

2 Professor emeritus.
}

2014a), a figure that includes over 40,000 younger people, i.e., 65 years of age or below, whose needs usually fall outside of mainstream service provision and support (Roach, Keady, Bee, \& Williams, 2014). Broadly speaking, in the UK, two thirds of the total number of people with dementia live at home with one third living alone: the total number of people with dementia living in the UK is expected to reach over 2 million by 2051 (Alzheimer's Society's, 2015 p. 3).

The most significant risk factor for the onset of a dementia is age, with one in five people over 80 having a type of dementia with Alzheimer's disease being the most common in both younger and older people (Alzheimer's Society's, 2014b). Despite some promising initial results from the acetylcholinesterase 
inhibitors, there are currently no pharmacological treatments to cure the condition and psychosocial interventions are promoted as the first step in treatment although their efficacy remains to be determined (NICE-SCIE, 2007). Depending upon a number of factors, such as existing co-morbidities, age at diagnosis and at what point in the stage of dementia a diagnosis is made, life expectancy can vary considerably (Xie, Brayne, \& Matthews, 2008), with some influential policy reports and commentators advocating for dementia to be categorised as a terminal illness (Alzheimer's Research Trust's, 2010; Department of Health [DH], 2009) that requires a palliative care approach (Iliffe, 2013).

Over a decade ago now, and perhaps as a commentary on this prevailing trend, Alzheimer's Australia (2003) confidently asserted that the 'dementia epidemic has arrived' (p.iv) and argued that a commitment to increasing the health span for people with dementia is best served through a combination of early intervention, improvement in diagnosis and the provision of cost-effective pharmacotherapies. Eight years later, a World Alzheimer Report on early diagnosis and intervention expanded these perceived benefits to include: personal relief gained from better understanding symptoms, opportunities to engage in risk reduction and having the ability to maximise personal decision making whilst capacity remained (Alzheimer's Disease International, 2011 p. 27). Interestingly, the same report stated that receiving a diagnosis of dementia was a fundamental human right and recommended that 'every country should have a national dementia strategy where the promotion of early diagnosis and intervention through awareness raising should be central to its formulation' (ADI, 2011 p. 7). This appears to be happening. For example, Scotland's second National Dementia Strategy [2013-16] (Scottish Executive, 2013) placed the improvement of diagnostic services and support as second of three main challenges, the others being the promotion of quality of life and well-being (placed first), and service transformation (placed third). In England, key commitment 1 of the first Prime Minister's Challenge on dementia (Department of Health, 2012a) is aligned to 'better diagnosis' and the need to increase diagnosis rates through regular (cognitive) checks for people aged over 65. Such a commitment is currently integrated into commissioning frameworks of local health and well-being boards and financially incentivised to reach improvement targets (Department of Health, 2012b), currently set at 75\% by 2017 across every area of England (Alzheimer's Society's, 2015 p. 12).

However, despite the considerable policy, practice and fiscal emphasis, a diagnosis of dementia is not the starting point for the experience of living with the condition. It is known from qualitative research involving those at the onset of their condition (Alzheimer's Society's, 2010a, 2010b; McCleary et al., 2013; Robinson, Ekman, Meleis, Winblad, \& Wahlund, 1997; Steeman, de Casterlé, Godderis, \& Grypdonck, 2006), influential reports (All-Party Parliamentary Group, 2012) and from the autobiographies written by people living with dementia (for a review, see Page \& Keady, 2010), that the first subtle signs of onset are often difficult for the person to understand and translate into their everyday frames of reference and meaning making. As an illustration, at the end of the 1980s in the first book written by a person with dementia, the Reverend Robert Davis described his initial encounter with (undiagnosed) dementia as follows: 'Deep within me I knew that something was terribly wrong with my mental processes' (Davis, 1989 p. 49). More recently, Mike Howorth, a man in his 80s living with Alzheimer's disease in the UK, shared that, before seeking professional help, he had felt 'a bit down for a number of years' and had aligned the (very) early, subtle changes to his memory and personality traits to a life event and 'some minor problems in our marriage' (Ward, Howorth, Wilkinson, Campbell, \& Keady, 2012 p. 292), thus repositioning the occurrence as 'normal' but remaining vigilant over its constant presence in his life. More importantly, the experience was kept a secret.

The journey to a diagnosis of dementia is seldom a straightforward and linear process. An important recent contribution to reframing dementia through a social model of disability underpinned by a Human Rights-Based Approach - further highlighted how the lateness, or lack of diagnosis, may be a result of the present inability of dementia organisations to fully challenge the 'dominant medical model' (Mental Health Foundation, 2015 p. 36). Dementia organisations thus continue maintaining the current status quo. A more informed exploration of the social processes involved in seeking and obtaining a diagnosis of dementia may therefore be seen as a timely contribution. By analysing a subset of data from a multi-site study conducted in four memory clinics in England (Manthorpe et al., 2011), this article will shed light on this overlooked topic area by exploring the following research aims: (1) to investigate the subjective experience of those living with undiagnosed and then, over time, diagnosed dementia; (2) to elicit the meanings that such transitions hold for those concerned.

\section{Methods}

Context: This qualitative study took place through three research centres within England and with four research site locations. The research sites ranged from an inner London borough to two sites in the North West and North East of England, which were quite similar in population and demographic characteristics, as well as a more rural site also based in the North East of England. There were 53 participants involved in the main study, 27 people with reported memory problems and 26 carers; this larger data set is reported elsewhere (Manthorpe et al., 2011; Abley et al., 2013; Manthorpe et al., 2013; Samsi et al., 2014). However, not all participants on the main study consented to two interviews and not all then went on to receive a diagnosis of dementia (Manthorpe et al., 2011). This present paper reports only on a subset of the data, the five participants and their carers and two people living alone, who consented to undertake two interviews, undertook both interviews and then had received a diagnosis of dementia by the time of second interview. Data are spread across the four research sites. The study was granted ethical approval by Newcastle and North Tyneside REC 1 and local permissions were received.

\section{Sample}

The overall project used purposive sampling for the study and the research team worked closely with memory services in the four locations to recruit patients from the service. Where it was possible, the study sought to engage both the person with undiagnosed/diagnosed dementia and their family carer so that a joint narrative of experience could be obtained. Semistructured interviews used a topic guide and the questions 
explored the experience of the assessment process as well as the process of diagnosis disclosure and subsequent adjustment processes. Interviews at both time points were conducted in the participant's own homes by one of the research team (KS; CA; SC), and participants were interviewed on their own or together, as desired by the dyad. Of the seven people with undiagnosed/diagnosed dementia, three were female and four were male [age range 68 to 77]; of the five co-resident participants, three were in a spousal relationship, one in a parent/child relationship and one couple were identified as being friends living together. Four of the carers in this sample were female and one was male [age range 46 to 73]. All participants were living in their own homes at the time of both interviews and the previous occupations of participants diagnosed with dementia ranged from a domestic cleaner to a geologist. All participants were retired except one, the 46-year-old carer of a 71-year-old parent who listed her occupation as 'carer.' They all identified themselves as White British. By the time of the second interview, the following range of diagnostic outcomes had been shared: Alzheimer's disease $\times 3$, unspecified type $\times 2$, vascular dementia $\times 1$ and Lewy body dementia $\times 1$. All participants had been prescribed acetylcholinesterase inhibitors by the time of the second interview except the participant with vascular dementia.

\section{Data analysis}

As in the main study, data analysis of this sample was based on the constant comparative method taken from a grounded theory approach (Glaser, 1978; Glaser \& Strauss, 1967). One of the research centres took a lead and co-ordinating role in the development of the subset thematic table by reading each interview set as a whole to allow the overall meanings of the participants' experiences to be seen in context. Only then was the data fractured through the coding process. Descriptive categories and underpinning phases which bridged the longitudinal nature of the diagnostic experiences were shared across the analysis team, which included the three researchers and three of the lead investigators (JB; JM; JK). A software programme (NVivo 10) was used to manage the data in this sample.

To help identify participants in the findings that follow, we have coded each participant with undiagnosed/diagnosed dementia as P; carer as $\mathrm{C}$; being in a relationship as R; living alone as LA; the number allocated to the participating dyad as $1-5$ and for those living alone $6-7$; and time 1 or time 2 interviews as T1 and T2, respectively. This coding is hyphenated.

\section{Findings}

Analysis of the sample is displayed in Fig. 1, and we have based the data reporting on the left to right flow of the heuristic, ending with a commentary on the underlying core category.

\section{Phase 1: becoming self-aware $\rightarrow$ seeking outside help}

Becoming self-aware involved a gradual acceptance that something out of the ordinary was happening in the context of everyday life, and that such events were cumulative, unremitting and unable to be controlled. As one participant shared, 'I could tell that things were changing with my mind' (P-R-4-T1). The triggers that commenced this active cycle of self-monitoring included memory lapses, repeated mistake making in familiar routines and word finding difficulties. These first signs of undiagnosed dementia were embedded within biographical, family, social and cultural contexts and were identity driven, leading to multiple meanings and interpretations applied to their occurrence(s). Importantly, such signs were not immediately aligned by the person to the existence of a dementia. From the presented data, the only exception to this was if the person experiencing these undiagnosed signs had had previous exposure to dementia, such as through a family history or caring responsibilities, including the experience of being a care assistant in a care home for people with dementia. In such circumstances, there was a heightened awareness that 'it might be dementia.' However, this suspicion did not mean that concerns were automatically opened up to other family

\section{Transition from pre-diagnosis to a diagnosis of dementia}
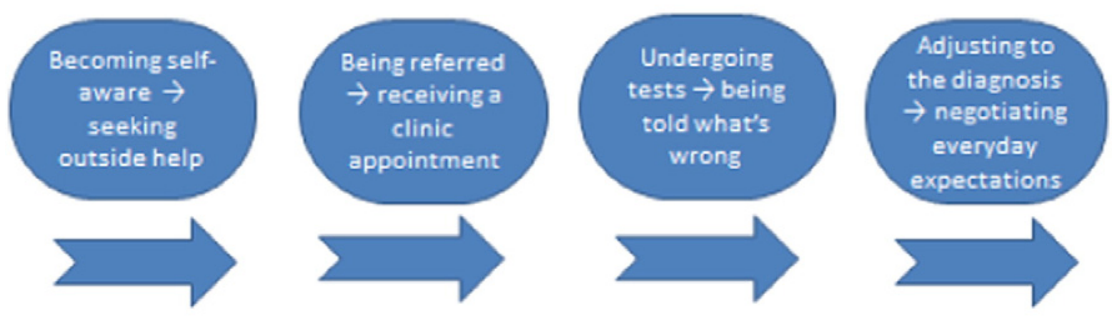

\section{Living with uncertainty}

Time

Fig. 1. Transition from pre-diagnosis to a diagnosis of dementia. 
members and/or outside help sought from the person's general practitioner (GP) for investigation.

The time and transition between becoming self-aware to seeking outside help depended upon a number of relational factors, such as the following: How are problems within the family usually discussed and made visible? Who usually takes responsibility for articulating problems? Is health prioritised or acknowledged? What is the history of the family or relationship? The following data extract and reflective commentary from the friendship relationship at time 1 best illustrates the initial (subjective) reasoning of new-found and unexplained events and then the complex set of emotional transactions and interpersonal negotiations necessary to seek outside help:

'No, I go with the flow, I mean if you put your hand ... yourself into the hands of somebody who is going to help, or think they can help, erm, hope they can help, I have been aware that my brain is not as sharp as it has been, but then you're 72 and you think it's ageing. It's erm, but erm, I've been curious about the bangs on the head ... and thought could it be some brain damage with it? ... when I fell in the park?' (P-R-2-T1).

From the friend's perspective (carer), the same situation was understood as follows:

'.. and then there were all the bills, so she knows what's coming in and what's going out and projects what we're going to need, and things like that, but she weeps over them now because she can't get the figures right ... Because she transposes the figures or she gets...she just writes the number down wrong ... and it was really distressing her and one or two other things. So I suggested that she went for a check-up, you know, like a M.O.T.' (C-R-2-T1).

For the carer, comparing her live-in friend's need for a cognitive health screen at the GP to the need for a car to pass its annual M.O.T. [independent Ministry of Transport mechanical check to remain roadworthy] was the reframing of events necessary to persuade her friend to seek a medical consultation. However, it was only at the time of the second interview that it was revealed that it took over two years to reach this outcome and was the result of persistent pressure, albeit from within the boundaries of a long-standing and caring relationship. If the person living with undiagnosed dementia does not want to acknowledge the (potential) seriousness of events, listen to the concerns of others or believe that their memory lapses [or other sensory changes] are manageable within the boundaries of everyday life, then the road to a diagnosis - if it happens at all may well be long and ripe for family/relational conflict.

However, it was reached that all participants in this study had obviously sought outside help and this transition paved the way for the next phase of the diagnostic process.

\section{Phase 2: being referred $\rightarrow$ receiving a clinic appointment}

All referrals into this study came from a participating memory clinic; similarly, all referrals to the memory clinics came from the undiagnosed person's GP. As outlined in the previous phase, this chain of events started only when the person living with undiagnosed dementia presented themselves to their GP to 'see what was happening' (P-LA-6-T1). All participants experienced varying degrees of memory problems at the time of first presentation to the GP and thereby all expected to be 'tested' [participant wording] in some way to find out what was wrong/happening. How this testing was to take place, in what form and for how long were unknown.

On the other hand, all participants recalled that the 'test' was done by their GP but none could remember being given the score they had achieved upon its completion, and it was intimated in the available data that the GP was sat behind a desk whilst the cognitive screen/test was being performed. No participant was able to share the name of the screening test that they had completed. Similarly, it was clear that by the end of this first consultation, no one was expecting their GP to refer them on to another service, and certainly not one with a different name, in a different building (often situated in another part of the city/locality) and to meet another set of staff with an array of work titles. As one participant succinctly stated, 'at the end of it [the screening assessment] I thought I was generally doing OK' (P-R-1-T1).

In this respect, all participants subsequently received the invitation to attend the memory clinic by an appointment letter sent to their home address. This process of waiting for the letter to arrive and then the underlying anxiety attached to the referral details contained therein should not be underestimated. In many ways, the knowledge that their initial consultation and results of the 'test' had warranted a more detailed investigation in a specialist centre provoked a range of emotions - and actions - among participants. For example, one participant with a professional background in technology (P-R-4) searched the internet for more information about what a memory clinic was, and it was at this point that he found a tie-in between a memory clinic and dementia. Similarly, once received, the appointment letter contained the name and directions to the memory clinic, a time to be present by and at least one name of a member of staff to whom they were to report/see. Drawing on local knowledge, one couple in the study (P-R-3 and C-R-3) knew immediately that the address provided on the appointment letter positioned the memory clinic within an older person's mental health assessment unit which, despite all the best intentions, carried its own stigma in the local community.

The wait for an appointment at the memory clinic ranged from a few weeks to over two months. Whilst there was a mixture of anxiety and expectation in waiting for the appointment date to come around, no participant considered the possibility that they would be ineligible for (any) available treatment or support should something serious be found to be wrong.

\section{Phase 3: undergoing tests $\rightarrow$ being told what's wrong}

The four participating memory clinics were busy environments and had clear protocols for the diagnostic pathway. However, it is uncertain if this information was shared with study participants over the course of their contact or if it was available to access in alternative ways. This is important as the route to a diagnosis of dementia can be a protracted and complex process - as seen in this study - and those entering this phase of their diagnostic journey were, at times, unprepared for how long it would take. Indeed, participants held more direct and expedient beliefs about the workings of a specialist service, as this slice of data attests 'it's just the not 
knowing if it is something that's wrong with you, or if it is just forgetfulness. I just want it over ... quickly' (P-LA-7-T1).

To reach this state of knowing, it had been necessary for each of the participants to undergo a battery of neuropsychological assessments and a brain scan. This was the same procedure for each of the participants in the study and in line with best practice evidence and policy guidance (DH, 2009). However, the time taken to undergo these assessments and then reach an authoritative decision on the clinical type and stage of the presented dementia was different in each of the seven cases. This is perhaps not surprising, and this difference should not, in any way, be construed as a criticism of the memory clinic teams and their professionalism; for example, two of the sample were eventually diagnosed with dementia of an 'unspecified type' after a robust, protracted and highly specialist set of repeat assessments that took many visits to the memory clinic and NHS support services to conclude. Rather, the main point to grasp here is the meaning that participants attached to the process of undergoing the testing procedure, the process of waiting to be told what was wrong and the impact that such events had on their everyday lives. These two quotes help to illustrate this dilemma:

'They spoke to me and [names her husband]. He gave [husband] a questionnaire I think it was that he had to ... I don't know if he had to tick or maybe it was like out of so many, one, two, three ... what was I? ... And he asked me questions, and then he asked me different questions. Just trying to think what it was again ... It was like a test really to see about my memory. He said it would be the first of quite a few visits' (P-R-1-T2).

'... and he couldn't answer the questions, and she'd [memory clinic psychiatrist] actually wrote down in the notes that he was a milkman all his life, where he only did ... well, he was an accountant. He did the milk round for a few years when he was 12 or something ... I feel I have to prompt the doctor as well as my dad' (C-R-5-T2).

These tests for those in the sample eventually led to a diagnosis of dementia which was provided by memory clinic staff. Reactions to the diagnosis ranged from shock and disbelief to calm acceptance and self-affirmation that their suspicions had been right all along. In this latter instance, previous family exposure to dementia helped but it was a double-edge sword: composure was intertwined with an intimate knowledge of the future.

Phase 4: adjusting to the diagnosis $\rightarrow$ negotiating everyday expectations

Contrary to expectations, the sharing of a diagnosis did not wholly satisfy the process of knowing for all concerned in the study. New questions were brought to the surface, some practical, some mundane and some existential; for example, How long is this stage of dementia going to last? [P-R-4-T2]; Is it still possible to drive my car? (P-LA-7-T2]; Can I still make us our tea? [P-R-1-T2]; What can I do now that I have this thing? [P-R-3T2]; Why did this have to happen to me? [P-LA-6-T2]. These threats to personal identity and agency were rooted in the everyday and all were profound in their implications and in the meanings that participants attached to their new-found situation.

This is a concern as, aside from the prescription of acetylcholinesterase inhibitors to six of the seven participants in the study, there did not appear to be any coherent form of psychological or psychosocial support offered to participants and the eventual transition between memory clinic $\rightarrow$ home $\rightarrow$ GP and/or community support [should it be needed] was as stark as this text makes it appear. For services, there was an expectation that life would return to normal supported by the follow-up appointments to monitor medication use. However, this faith appears misplaced as, from the data, a diagnosis of dementia simply magnified any fault-lines in the person's abilities to adapt to new situations and shone the brightest of spotlights on the functioning of existing relationships. Whilst lengthy, this conversational exchange between two study participants helps to illuminate this concern:

Husband: "I do tend to think that if I put one word out of place you snap a bit quick [directed to person with dementia], or her mood can change a bit quicker than it used to shall we say. [directed to the interviewer]' (C-3-R-T2).

Wife: 'That is because I am feeling vulnerable isn't it, so if somebody is getting at me about something, something I might not have done...' (P-3-R-T2).

Husband: 'It takes you a while to come out of it. [directed to person with dementia]' (C-3-R-T2).

Wife: 'I am going to sort of snap back and, to be honest with you, I would hate it if I couldn't do that because then I'd be like a little frightened puppy. I don't want to get to that stage, you've got to be ... I know it's not nice if somebody is having heated words or what have you, but I have to deal with that in my own way so that I don't feel too crushed' (P-3-R-T2).

In the final few words of this exchange, the use of the personal pronoun 'I' together with the adjective 'crushed' reveals clues about the participant's state of mind and the threat to her personal identity - and the long-standing relationship - posed by the existence and diagnosis of dementia. Perhaps this is a lot to read into a few words, but at the very least the couple required help to express their feelings in coming to terms with the diagnosis. Without such help, the consequences are likely to be ongoing interpersonal conflict instead of resolution and adaptation.

\section{Underlying core category: 'living with uncertainty'}

As Fig. 1 indicates 'living with uncertainty' is a status passage running throughout each of the four sequential phases. In defining the core category this way, we are suggesting that there is little, or no, stability at just about any point in the preand immediate post-diagnostic period and even when a potential definitive marker is brought into play, for example 
through the sharing of a diagnosis of Alzheimer's disease with participants, uncertainty remains. For instance, How long will each stage of dementia last? What treatments will work? What will happen next? Returning everyday life to a pattern of normality from within a frame of uncertainty and diminishing cognitive abilities is hugely challenging for all concerned.

\section{Discussion}

Using a longitudinal qualitative design, this paper has reported on the development of four distinct and sequential phases that describe the onset, self-recognition, help-seeking and impact of receiving a diagnosis of dementia. Each of the four phases is underpinned by the everyday experience of 'living with uncertainty', which ranged from the mundane (i.e., waiting for the arrival of a memory clinic appointment letter and what it would say) to the profound (i.e., concern if the diagnosis puts your children at an increased risk of 'getting the same in the future' [P-R-5-T2]).

Due to the current media interest in dementia and the alignment of dementia to the public health agenda (Alzheimer's Disease International, 2012), this study has been timely in exploring the impact of these messages on people accessing memory clinic services. Indeed, once the decision has been reached to seek outside help on what is causing the memory problems, for example, there is a clear feeling from those who went on to obtain a diagnosis of dementia that they did so because they believed that something could be done to help. In six of the seven cases, this was through the prescription of acetylcholinesterase inhibitors, although the data revealed that more psychosocial support was necessary (Moniz-Cook \& Manthorpe, 2009). Worryingly, for the person living with Vascular dementia, no ongoing support was offered once the diagnosis was made. It is hard to draw (inter)national comparisons from just one case, but it does seem that those with vascular dementia are caught in a particularly vulnerable position in that they do not qualify for the prescription of acetylcholinesterase inhibitors (which may or may not be effective), yet their vascular needs are not systematically addressed as they would have been should the person have suffered a stroke or other vascular incident (Swarbrick et al., 2012). To a certain extent, in England, the second Prime Minister's Challenge on dementia (Department of Health, 2015) has attempted to respond to such needs by setting an average national target of six weeks between GP referral to memory clinic appointment and that, post-diagnosis, all people with dementia should have equal access to a range of support that may include personalised information, a dementia adviser and other helping such as counselling and 'ongoing specialist care provided by specialist nurses' (p. 16). Time will tell if these policy ambitions translate to meaningful change and opportunities on the ground.

Our research also shows that the journey to a diagnosis starts with the person's illness recognition. Here, there are parallels to the work of Harman and Clare (2006) and echoes in the exploratory work in mild dementia conducted through the Hughes Hall Project for Later Life in the late 1980s and, in particular, Pollitt, O'Connor \& Anderson (1989) astute observation from this study that 'until the carers or relatives make a conceptual leap from seeing the condition as normal to securing it as abnormal, it will be difficult to offer appropriate help to prevent the build-up of stress or crisis occurring' (p. 273). Whilst time has moved on, especially in moving the opinions of people with dementia to the centre of the debate, there remains a salient truth in Pollitt et al.'s (1989) words in that those involved in the process of illness recognition may well adopt different positions and be interpreting events and processing their meaning(s) through their own, and thereby a separate lens of understanding. How those positions are then negotiated and played out in everyday life become crucial determinants to illness presentation to outside agencies, as seen in the M.O.T. example in this paper and the two year dialogue to achieve a desired outcome. Finding ways to smooth the transition between (personal) illness recognition to (outside) illness presentation becomes key determinants of service awareness, support, quality and an opportunity to live well with dementia.

Arguably, the processes underpinning such transitions is not confined to dementia and has 'carry through' to other types of sudden onset (e.g. stroke) or gradual onset (e.g. Parkinson's disease), chronic conditions. Therapeutic understandings have shown how there needs to be psychosocial support to enable families to 'work through' the transition phases and the ongoing challenges of living with a chronic or terminal condition, such as that proposed in John Rolland's 'therapeutic quadrangle' where family systems are seen to interact with the chronic condition within and between three dimensions: (i) the psychosocial types of illness; (ii) the time phases of chronic illness and (iii) components of family functioning (Rolland, 1988, 1994). Alarmingly, no participants in this subset appeared to have been offered any kind of psychosocial intervention to help manage the process of diagnosis, or transition from a family living with undiagnosed memory problems to a family living with dementia. On this latter point, as Joy Watson, a person living with young onset dementia has recently shared, it is important to make dementia 'a topic that can be embraced rather than feared and help those living with it to live well' (Watson, 2016 p. 5). Greater public awareness coupled with meaningful personal empowerment of people living with dementia through choice, opportunities for everyday social engagement, continuity of identity and interaction with dementia friendly communities may well help to challenge the stigma that still surrounds the condition (Alzheimer's Society's, 2010b) and promote a rationale for obtaining a diagnosis in the first place (ADI, 2011; Alzheimer's Society, 2014a, 2014b; DH, 2015).

Finally, if meaningful progress in dementia care and awareness is to be made, and as far as it is both realistic and practicable, 'certainty' needs to replace 'uncertainty' throughout each of the four phases outlined in this article. As an illustration, and to take but one example, in phase 3 'undergoing tests' there have been precious few studies that have explored the experience of neuropsychological assessment in dementia from the patient's perspective (Samsi et al., 2014). However, of the studies that have been reported (see, for example, Keady \& Gilliard, 2002), uncertainty over the meaning of the assessments/tests and what a score actually denotes are regular features of captured experience, as they are in this sample. This speaks of a need for more transparent information about the meaning and function of neuropsychological assessment to help better prepare and inform those on its receiving end: from explanatory information on the internet through to 
personalised handouts at the memory clinic or in follow-up. Indeed, as we have written about elsewhere, participants in the larger study wanted more clarity about the length of the diagnostic process and what information needs might help in their adjustment and preparation for being told what is wrong (Manthorpe et al., 2011; Abley et al., 2013; Samsi et al., 2014). It would also be helpful for patients to make contact with a named person between appointments to talk about any worries or anxieties (Samsi et al., 2014). Arguably, enacting these and other person-centred initiatives, and evaluating their outcome, would help provide real substance to the meta-narrative of 'living well with dementia' that permeates the dementia field at present (Alzheimer's Society's, 2014b; DH, 2012a) and act as a solid foundation for change.

\section{Study limitations}

The limitations of the study need to be acknowledged. First, the sample comprises solely of White British people, and this is not representative of the ethnic diversity that exists in each of the data collection sites. We would suggest that additional work with other population groups should be conducted so that a more rounded experience can be presented and compared. Second, the sample size is small $(n=12)$, although qualitative research does not make any claim over the generalisability of the findings. However, future work would benefit from either a larger sample or more visits to those participants during the time of participation so as to further increase sensitivity to the emerging issues. Third, the length of study did not allow for longitudinal engagement beyond the two visits reported in the study. Additional longitudinal research and/or practitioner research in this area would help provide a more sensitising approach to data reporting. Fourth, this sample is not representative of those older populations, who may go on living with 'undiagnosed dementia' in the community (Mitchell, McCollum, \& Monaghan, 2013) until such a time as they experience a health or social care crisis and are either admitted to a long term nursing facility, or acute hospital, where they may then gain a formal diagnosis.

\section{Conclusion}

This study has sought to describe the sequential phases that go from self-recognition through to a diagnosis of dementia shared in the memory clinic and its immediate aftermath. This resulted in a longitudinal engagement by the research team with the study participants and extended knowledge on the lived reality of the experience. This methodological approach enhanced the authenticity and trustworthiness of the study findings. The wider implications of the study relate to the need to delimit uncertainty in all aspects of the transitions into and from a diagnosis of dementia so that people living with condition and their support networks can retain their personhood, well-being and connections to their community for as long as is possible.

\section{Acknowledgements}

The project team thanks all the study participants for their insights and wisdom. We acknowledge the NHS administrators at each of the four memory services and the study's local and national advisory groups for their assistance and expertise. Our thanks also to other members of the research team, Kalpa Kharicha, and co-investigators of this study, Steve Iliffe, University College London; Vari Drennan, St. George's University of London; Claire Goodman, University of Hertfordshire; and James Warner, Central and North West Foundation Trust. We are grateful to Linda Welch, The University of Manchester, for helping to coordinate this paper. Finally, we acknowledge the National Institute for Health Research (NIHR) Service Delivery and Organisation Programme that funded the project (project number 08/1809/229).

\section{References}

Abley, C., Manthorpe, J., Bond, J., Keady, J., Samsi, K., Campbell, S., Watts, S., \& Robinson, L. (2013). Patients' and carers' views on communication and information provision when undergoing assessments in memory services. Journal of Health Services Research and Policy, 18(3), 167-173.

All-Party Parliamentary Group (2012). Unlocking diagnosis: The key to improving the lives of people with dementia. All-Party Parliamentary Group report 2012. London: House of Commons (www.alzheimers.org.uk/ site/scripts/download_info.php?fileID=1457).

Alzheimer's Australia (2003). The dementia epidemic: Economic impact and positive solutions for Australia. Canberra: Alzheimer's Australia (https://fightdementia. org.au/sites/default/files/20030300_Nat_AE_FullDemEpEconImpPos Solutions.pdf)

Alzheimer's Disease International (2009). World Alzheimer Report 2009. London: Alzheimer's Disease International (www.alz.co.uk/research/files/ WorldAlzheimerReport.pdf).

Alzheimer's Disease International (2011). World Alzheimer report 2011: The benefits of early diagnosis and intervention. London: Alzheimer's Disease International (https://www.alz.co.uk/research/WorldAlzheimerReport2011. pdf).

Alzheimer's Disease International (2012). Dementia: A public health priority. London: Alzheimer's Disease International (http://whqlibdoc.who.int/ publications/2012/9789241564458_eng.pdf).

Alzheimer's Research Trust (2010). Dementia 2010. London: Alzheimer's Research Trust (www.dementia2010.org).

Alzheimer's Society (2010a). My name is not dementia: Literature review. London: Alzheimer's Society (www.alzheimers.org.uk/site/scripts/download_info. php?fileID=876).

Alzheimer's Society (2010b). My name is not dementia: People with dementia discuss quality of life indicators. London: Alzheimer's Society (www. alzheimers.org.uk/site/scripts/download_info.php?fileID=876).

Alzheimer's Society (2014a). Dementia UK (2014 ed.). London: Alzheimer's Society (www.alzheimers.org.uk/site/scripts/download.php?fileID=2317).

Alzheimer's Society (2014b). Dementia 2014: Opportunity for change. London: Alzheimer's Society (www.alzheimers.org.uk/site/scripts/download_info. php?fileID =2317)

Alzheimer's Society (2015). Dementia 2015: Aiming higher to transform lives. London: Alzheimer's Society (www.alzheimers.org.uk/site/scripts/download. php?fileID=2700).

Davis, R. (1989). My journey into Alzheimer's disease. Amersham-on-the-Hill, Buckinghamshire: Scripture Press.

Department of Health (2009). Living well with dementia: A national dementia strategy. London: Department of Health (www.gov.uk/government/ publications/living-well-with-dementia-a-national-dementia-strategy).

Department of Health (2012a). Prime minister's challenge on dementia: Delivering major improvements in dementia care and research by 2015. London: Department of Health (www.gov.uk/government/uploads/system/ uploads/attachment_data/file/215101/dh_133176.pdf).

Department of Health (2012b). NHS outcomes framework 2013 to 2014. London: Department of Health (www.gov.uk/government/publications/nhsoutcomes-framework-2013-to-2014).

Department of Health (2015). Prime minister's challenge on dementia 2020. London: Department of Health (www.gov.uk/government/uploads/system/ uploads/attachment_data/file/414344/pm-dementia2020.pdf).

Glaser, B. G. (1978). Theoretical sensitivity. Mill Valley, CA: Sociology Press.

Glaser, B. G., \& Strauss, A. L. (1967). The discovery of grounded theory: Strategies for qualitative research. Chicago: Aldine.

Harman, G., \& Clare, L. (2006). Illness representations and lived experience in early-stage dementia. Qualitative Health Research, 16(4), 484-502.

Iliffe, S. (2013). Commissioning services for people with dementia: How to get it right. The Psychiatrist, 37, 121-123. 
Keady, J., \& Gilliard, J. (2002). Testing times: The experience of neuropsychological assessment for people with suspected Alzheimer's disease. In P. B. Harris (Ed.), The person with Alzheimer's disease: Pathways to understanding the experience (pp. 3-28). Baltimore: The Johns Hopkins University Press.

McCleary, L., Persaud, M., Hum, S., Pimlott, N. J., Cohen, C. A., Koehn, S., ... Emerson, V. F. (2013). Pathways to dementia diagnosis among South Asian Canadians. Dementia: The International Journal of Social Research and Practice, $12,769-789$.

Manthorpe, J., Samsi, K., Campbell, S., Abley, C., Keady, J., Bond, J., Watts, S., Robinson, L., Gemski, A., Warner, J., Goodman, C., Drennan, V., \& Iliffe, S. (2011). The transition from cognitive impairment to dementia: Older people's experiences. Final project report to National Institute for Health Research: Service Deliver Organisation programme (Project number: 08/1809/229, http:/www.kcl.ac.uk/sspp/policy-institute/scwru/pubs/2011). manthorpeetal2011transitionfinalreport.pdf)..

Manthorpe, J., Samsi, K., Campbell, S., Abley, C., Keady, J., Bond, J., Watts, S., Robinson, L., Warner, J., \& Iliffe, S. (2013). From forgetfulness to dementia: clinical and commissioning implications of diagnostic experiences. British Journal of General Practice, 63(606), e69-e75.

Mental Health Foundation (2015). Dementia, rights, and the social model of disability: A new direction for policy and practice? Mental Health Foundation Policy Discussion. London: Mental Health Foundation (www. mentalhealth.org.uk/content/.../dementia-rights-key-summary.pdf).

Mitchell, G., McCollum, P., \& Monaghan, C. (2013). Disclosure of a diagnosis of dementia: A background to the phenomenon. Nursing Older People, 25(10), $16-21$.

Moniz-Cook, E., \& Manthorpe, J. (Eds.). (2009). Early psychosocial interventions in dementia. London: Jessica Kingsley.

NICE-SCIE (2007). Dementia: Supporting people with dementia and their carers in health and social care. NICE clinical practice guideline 42. London: National Institute for Health and Clinical Excellence (www.nice.org.uk/guidance/ cg42/chapter/guidance).

Page, S., \& Keady, J. (2010). Sharing stories: A meta-ethnographic analysis of twelve autobiographies written by people with dementia between 1989 and 2007. Ageing and Society, 30(3), 511-526.

Pollitt, P. A., O'Connor, D. W., \& Anderson, I. (1989). Mild dementia: Perceptions and problems. Ageing and Society, 9, 261-275.
Roach, P., Keady, J., Bee, P., \& Williams, S. (2014). 'We can't keep going on like this': Identifying family storylines in young onset dementia. Ageing and Society, 34(8), 1397-1426.

Robinson, P., Ekman, S. L., Meleis, A., Winblad, B., \& Wahlund, L. O. (1997). Suffering in silence: The experience of early memory loss. Health Care in Later Life, 2, 107-120.

Rolland, J. S. (1988). A conceptual model of chronic and life-threatening Illness and its impact on families. In C. S. Chilman, F. M. Cox, \& E. W. Nunnally (Eds.), Families in trouble: Knowledge and practice perspectives for professionals in the human services (pp. 17-68). Newbury Park: Sage.

Rolland, J. S. (1994). Families, illness E disability. An integrative treatment model. New York: Basic Books.

Samsi, K., Abley, C., Campbell, S., Keady, J., Manthorpe, J., Robinson, L., Watts, S., \& Bond, J. (2014). Negotiating a Labyrinth: experiences of assessment and diagnostic journey in cognitive impairment and dementia. International Journal of Geriatric Psychiatry, 29(1), 58-67.

Scottish Executive (2013). Scotland's national dementia strategy: 2013-16. Edinburgh: Scottish Executive (www.gov.scot/Resource/0042/00423472. pdf).

Steeman, E., de Casterlé, B. D., Godderis, J., \& Grypdonck, M. (2006). Living with early-stage dementia: A review of qualitative studies. Journal of Advanced Nursing, 54(6), 722-738.

Swarbrick, C., Keady, J., Deaton, C., Reilly, S., Price, R., Howorth, M., ... Pendleton, N. (2012). Proposing a cardiac model for vascular dementia. British Journal of Nursing, 21(19), 1124.

Ward, R., Howorth, M., Wilkinson, H., Campbell, S., \& Keady, J. (2012). Supporting the friendships of people with dementia. Dementia: The International Journal of Social Research and Practice, 11(3), 287-303.

Watson, J. (2016). Is it possible to live well with dementia? Editorial. Dementia: The International Journal of Social Research and Practice, 15(1), 4-5.

Xie, J., Brayne, C., \& Matthews, F. E. (2008). Survival times in people with dementia: analysis from population based cohort study with 14 year follow-up. British Medical Journal, 336, 258-262. 